\title{
Investigation of Thin Film for High Emissivity Infrared Micro Emitter
}

\author{
Masahiko Mitsuhashi, Seishiro Ohya, Shiro Karasawa, Kenji Akimoto, \\ Masayuki Onoue and Setsuo Kodato \\ Kanagawa Industrial Technology Research Institute \\ 705-1 Simoimaizumi, Ebina-shi, Kanagawa 243-04, JAPAN
}

\begin{abstract}
Summary
A platinum infrared emitter by Joule's heat, about $0.5 \times 0.5 \mathrm{~mm}^{2}$ of a pattern size, has been fabricated with micro lithography process of the platinum film on a quartz glass substrate. A hafnium oxide buffer film was used. The heat characteristics of the emitter were examined with thermography and a spectroradiometer. The maximum temperature of the heating emitter is confirmed to be $600{ }^{\circ} \mathrm{C}$ at least. The platinum film emitter has the emissivity less than 0.1 and is nearly equivalent to gray body in wavelength 4-14 $\mu \mathrm{m}$. The emissivities of ceramics films on the platinum film were investigated to obtain the higher emissivity. The emissivities of oxide ceramics thin films are different from that of bulk targets and less than them. In Corning 7059 thin films, however, the higher emissivity values rather than that of the target is obtained at film thickness $6.7 \mu \mathrm{m}$ in wavelength $7-11 \mu \mathrm{m}$. The highest value of emissivity of the thick film was 0.96 at wavelength $9.5 \mu \mathrm{m}$.
\end{abstract}

Keywords: Infrared emitter, Emissivity, Thin film, Laser ablation, Ceramics

\section{INTRODUCTION}

There is a need for portable and inexpensive detection systems to monitor pollutant or hazardous gases. Gases of particular interest include hydrocarbon, hydro-sulfur and the oxide of nitrogen and carbon. One method of detecting these gases makes use of the infrared vibrational absorption of the particular gases. The infrared source of gas detection system is needed to tune the emission wavelength to the infrared vibration of the particular gas. The attenuation of this emission which passes through a sample of the atmosphere is a direct measure of the concentration of the gas. The emitter has been made of metal wire till now. In order to obtain the smaller infrared emitter, we adapted the technique of micro fabrication process of thin film pattern. The infrared rays are emitted by the Joule's heat of the thin film pattern. The feature of the thin film emitter is suitable for the designs of various radiant powers. We used platinum thin films, because of high melting point $\left(1772^{\circ} \mathrm{C}\right)$, chemical stability and confidence in industry. However, $\mathrm{Pt}$ film has low emissivity. The high emissivity coating films are necessary for the infrared micro emitter. The high emissivity of ceramics coating on metal was reported by the investigation for oxide films [1-3].

The purposes of this investigation are the production of infrared micro emitters and the high emissivity thin films suitable for gas detection. One points of this paper is production and estimation of Pt film resistive heater for the micro infrared emitter. Another point is high emissivity of Corning 7059 glass film.

\section{EXPERIMENT}

A) Production of micro infrared emitter

We used a quartz glass as a substrate. A hafnium oxide film was deposited on the glass substrate. Next a Pt film was deposited on the Hf oxide film. The Hf oxide film adhered the Pt film to the substrate, as a buffer layer. Moreover, this Hf oxide film was used as an insulator. The pre-treatment of the substrate was 5 minutes ultrasonic cleaning with trichloroethylene, acetone and ethanol, respectively.

The Hf film was made with electron beam vacuum deposition. The back pressure of this deposition was in 2 $\times 10^{-5}$ Torr. The temperature of the substrate during deposition was $300^{\circ} \mathrm{C}$. The source voltage of electron beam was $10 \mathrm{kV}$. The source current was $180 \mathrm{~mA}$. The deposition time was $120 \mathrm{sec}$. The thickness of Hf film was $80 \mathrm{~nm}$. This Hf film was oxidized under the thermal treatment of $700{ }^{\circ} \mathrm{C}$ and $\mathrm{O}_{2}$ gas flowing, for 2 hours.

The Pt film was made with RF magnetron sputtering deposition. The back pressure of this deposition was $2 \times 10^{-6}$ Torr. The temperature of the deposition was 250 
${ }^{\circ} \mathrm{C}$. The RF source voltage was $0.7 \mathrm{kV}$. The $\mathrm{RF}$ source current was $40 \mathrm{~mA}$. The RF power was $10 \mathrm{~W}$. The Argon gas pressure was maintained $3 \times 10^{-3}$ Torr. The deposition time was 2 hours. The thickness of the Pt film was about $200 \mathrm{~nm}$.

The Pt film emitter pattern was produced with electron beam lithography and a negative resist. The Pt film was etched with ECR microwave plasma etching. The patterned negative resist was used as an etching mask. The etching conditions were $34 \mathrm{~A}$ of magnetic current, $200 \mathrm{~W}$ of microwave power and $20 \mathrm{~W}$ of RF power. The flow rate of argon gas was $10 \mathrm{sccm}$. The etching time was 10 minutes, next 10 minutes for cooling of the resist mask. The etching speed of the Pt film was 12.5 $\mathrm{nm} / \mathrm{min}$. The etching speed of the resist pattern was 5 $\mathrm{nm} / \mathrm{min}$. The pattern size of the Pt film emitter was about $0.5 \times 0.5 \mathrm{~mm}^{2}$. The width of the Pt pattern line was $20 \mu \mathrm{m}$.

The distribution of temperature for the heated emitter was measured with thermography. The our necessary heating temperature for the emitter is $500{ }^{\circ} \mathrm{C}$ at least by Planck's law. The measuring system of thermography was Infra Scope, which made by Barns Engineering Division.

\section{B) Production and estimation of ceramics films}

We investigated the emissivities of ceramics films to obtain the higher emissivity. The ceramics thin films were deposited on $\mathrm{Pt}$ film/ Hf film buffer/ quartz glass substrate with laser ablation method. The size of the substrate was $25 \times 25 \times 1 \mathrm{~mm}^{3}$.

The ceramics targets of excimer laser ablation were barium borosilicate glass (Corning 7059), alumina, yttria-stabilized zirconia (YSZ), $\mathrm{SrTiO}_{3}$ (STO) and $6 \mathrm{H}$ silicon carbide. The substrate temperatures during depositions were $300{ }^{\circ} \mathrm{C}$. The back pressure was several $10^{-6}$ Torr. In the case of oxide films, the $\mathrm{O}_{2}$ gas pressure was maintained 10 mTorr during deposition. In SiC film deposition, the pressure was $2 \times 10^{-6}$ Torr with no gas introduced. The $\mathrm{KrF}$ excimer laser with $248 \mathrm{~nm}$ wavelength, $100 \mathrm{~mJ}$ energy, and $24 \mathrm{~ns}$ pulse width was focused to a spot size of $1 \times 3 \mathrm{~mm}^{2}$ on respective targets in a vacuum chamber. The power density was $3 \mathrm{~J} / \mathrm{cm}^{2}$. The substrate was located $4 \mathrm{~cm}$ from the targets. Depositions of Corning 7059 glass, alumina and YSZ were performed for 15-30 minutes at a laser repetition rate of $10 \mathrm{~Hz}$. Depositions of $\mathrm{SiC}$ and STO were performed for 20 minutes at a laser repetition rate of $2 \mathrm{~Hz}$. In order to investigate for the effect of emissivity on film thickness, the films of Corning 7059 glass and alumina were deposited with varying film thickness; The deposition time of Corning 7059 thick film was 40 minutes and the laser repetition rate of alumina thick film was $15 \mathrm{~Hz}$.

The infrared radiances and spectral emissivity of the ceramics films were measured with spectroradiometer, which made the model SA-200 by Barnes Engineering Division. This detector was a sandwich construction detector, consisting of $\mathrm{InSb}$ and $\mathrm{HgCdTe}$ photo diodes. The wavelength range covered was from 1.35 to 14.49 $\mu \mathrm{m}$. The samples were heated up to $500{ }^{\circ} \mathrm{C}$. These samples were joined to a resistive heater with $\mathrm{Ag}$ paste. The temperatures of samples $\left(25 \times 25 \times 1 \mathrm{~mm}^{3}\right)$ were measured with thermocouple touched on the surface of films, which was made of wires of $0.2 \mathrm{~mm}$ in diameter.

\section{RESULTS AND DISCUSSION}

\section{A) Results of infrared micro emitter}

Figure 1 is a thermograph of heating emitter at $300{ }^{\circ} \mathrm{C}$ at the part of Pt emitter pattern by electric power $465 \mathrm{~mW}$. The figure shows that the left part of a pattern is heating. This heating element has $22 \Omega$ of resistance, about $1 / 3$ value of whole pattern $\left(0.5 \times 0.5 \mathrm{~mm}^{2}\right)$. This figure shows that a quartz glass substrate became an infrared emitting element. The white line shows the pattern of the platinum film in the figure. The white part means highest temperature.

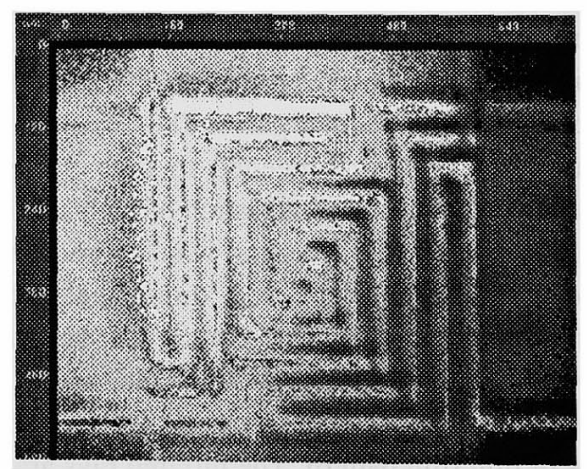

Fig. 1 Thermograph of a heating emitter at $300{ }^{\circ} \mathrm{C}$.

Figure 2 shows a correlation between temperature at a heating Pt pattern and electric power. The temperature of a heating Pt pattern was measured with Infra Scope. The measurement range of Infra Scope was until $600{ }^{\circ} \mathrm{C}$. The temperature of a heating $\mathrm{Pt}$ element was over range on electric power $652 \mathrm{~mW}$. The temperature of a heating element is confirmed to be $600{ }^{\circ} \mathrm{C}$ at least on electric power $652 \mathrm{~mW}$. 
Figure 3 shows the spectral radiances of a infrared micro emitter. These radiances are weak, because of small square of heating element. The thermal time constant of the infrared micro emitter was $17 \mathrm{msec}$. That of minimum coil heater of $\mathrm{Pt}$ wire (length: $0.4 \mathrm{~mm}$, diameter: 0.09 $\mathrm{mm}, 14$ turns, diameter of wire: $0.02 \mathrm{~mm}$ ) was $28 \mathrm{msec}$. The response of this micro emitter was faster than that of Pt coil heater.

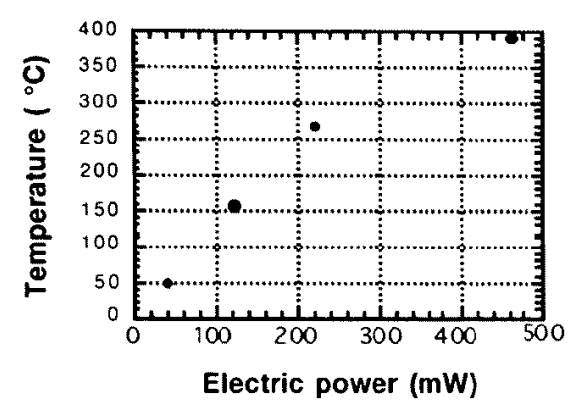

Fig. 2 Correlation between temperature and electric power of a heating emitter.

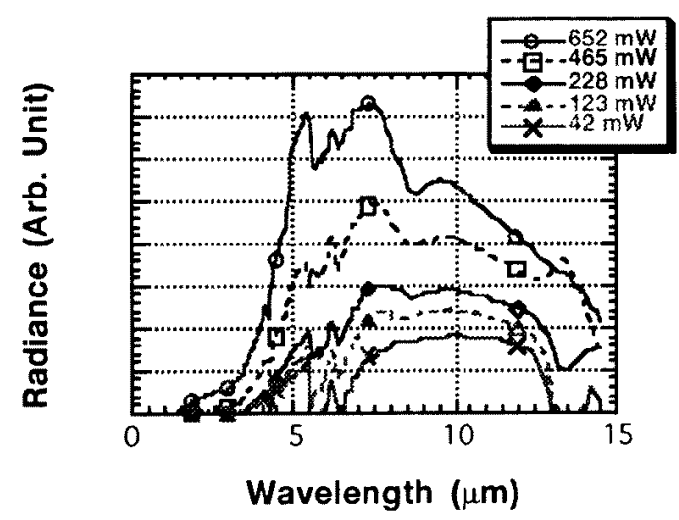

Fig. 3 Spectral radiances of a heated infrared emitter. The electric powers are $42,123,228,465$ and $652 \mathrm{~mW}$, from the bottom.

\section{B) Emissivities of ceramics films}

The thicknesses of deposited thin films of Corning 7059 , alumina, YSZ, silicon carbide and STO are $2 \mu \mathrm{m}, 400$ $\mathrm{nm}, 850 \mathrm{~nm}, 100 \mathrm{~nm}$ and $100 \mathrm{~nm}$ at least, respectively. The thicknesses of deposited thick films of Coming 7059 and alumina are $6.7 \mu \mathrm{m}$ and $600 \mathrm{~nm}$, respectively. These films have thickness variation. The emissivities of all films are higher than one of the Pt film. The emissivities of films are less than that of targets, according to results of the measured emissivities at $500{ }^{\circ} \mathrm{C}$.

Figure 4 shows the spectral emissivities of a silicon carbide film, a STO film and a Pt film. The Pt film has the emissivity less than 0.1 and is nearly equivalent to gray body in wavelength 4-14 $\mu \mathrm{m}$. The spectral emissivity of a STO thin film has three peaks, wavelength of about $3.5,7$ and $14 \mu \mathrm{m}$.

Figure 5 shows the spectral emissivities of a YSZ thin film and a YSZ bulk target. This film has a peak at wavelength of about $2.8 \mu \mathrm{m}$. In the case of wavelength over $10 \mu \mathrm{m}$, the emissivity of a YSZ target has over 1 . We think that this error is caused of two reasons. One reason is that those radiant intensities from the samples and a standard black body radiator are smaller in longer wavelength range. As a result, the ratio of signal and noise is a low value. Another reason is the influence of error for the temperature measurement of the samples.

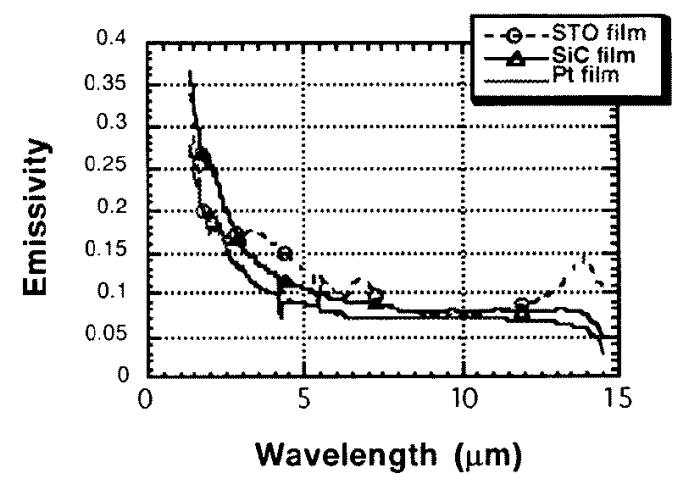

Fig. 4 Spectral emissivities of a SiC film, a STO film and a Pt film at $500{ }^{\circ} \mathrm{C}$.

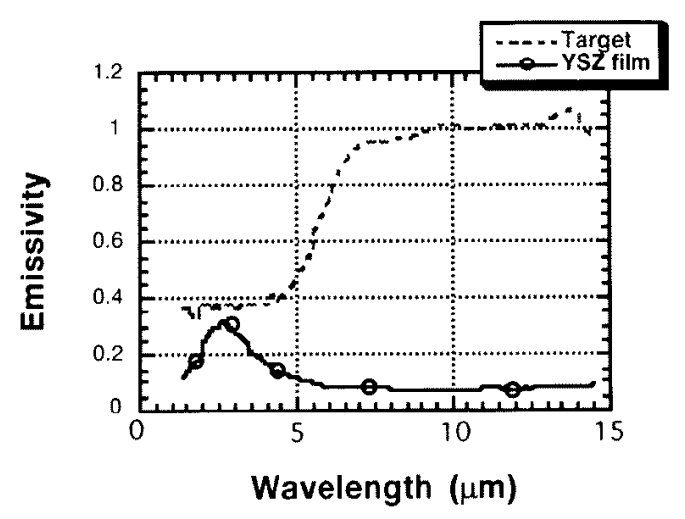

Fig. 5 Spectral emissivities of a YSZ thin film and a YSZ target at $500{ }^{\circ} \mathrm{C}$. 
Figure 6 shows the spectral emissivities of an alumina thin film $(200 \mathrm{~nm})$, an alumina thick film $(600 \mathrm{~nm})$ and an alumina target. The thin film has a broad peak at about $3.7 \mu \mathrm{m}$. The relation between the emissivities and thicknesses for alumina film was investigated by T.S.Eriksson et al. [1]. They reported that the low emissivity of the alumina film was obtained for the film thicknesses lower than $0.8 \mu \mathrm{m}$, whereas rather high emissivity could be obtained for films thicker than $3 \mu \mathrm{m}$.

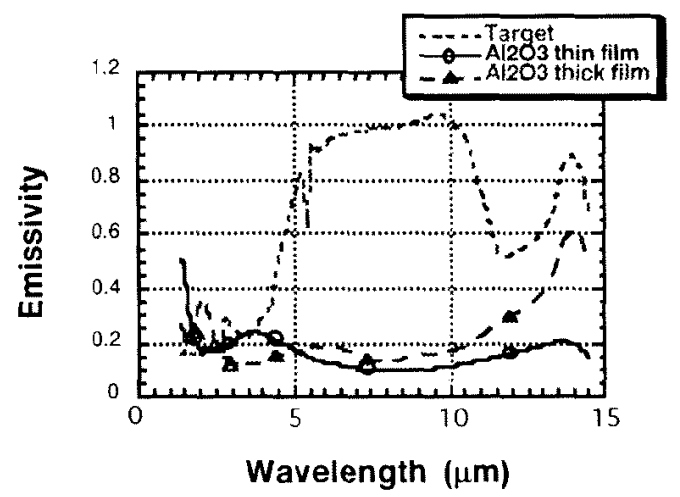

Fig. 6 Spectral emissivities of an alumina thin film, an alumina thick film and an alumina target at $500^{\circ} \mathrm{C}$.

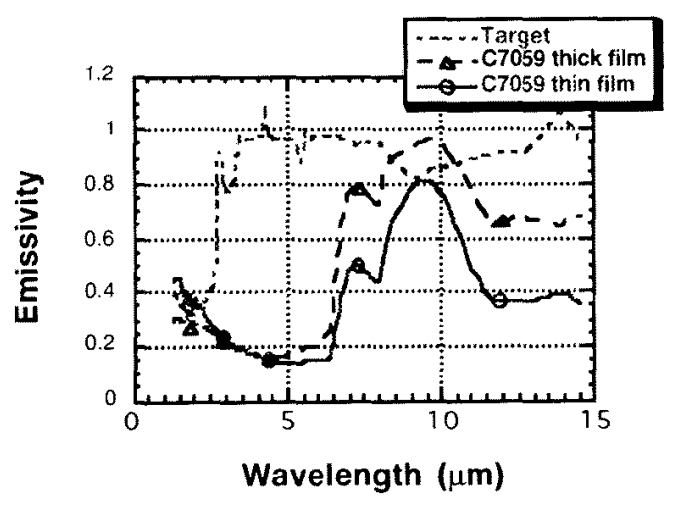

Fig. 7 Spectral emissivities of a Corning 7059 glass target, a thin film and a thick film at $500^{\circ} \mathrm{C}$.

Figure 7 shows the spectral emissivities for a target, a thin film $(2 \mu \mathrm{m})$ and a thick film $(6.7 \mu \mathrm{m})$ of Corning 7059 glass. The profiles of films have two peaks at wavelength of about 7 and $9.5 \mu \mathrm{m}$. In particular, the emissivity of the thick film is higher than that of the target in the range from 8.5 to $10.5 \mu \mathrm{m}$. The highest value of emissivity of the thick film is 0.96 at wavelength $9.5 \mu \mathrm{m}$. The same two peaks of emissivity for the glass film were reported by K. Kusabiraki et al. [2]. The wavelength of the reported main peak, however, was about $12 \mu \mathrm{m}$. We think that the reason of wavelength difference is caused in the film deposition and the concentration of impurity. The influence of impurities for glass coating was reported [3]. The glass reported by of $\mathrm{K}$. Kusabiraki et al. [2] was molten $\mathrm{Na}_{2} \mathrm{O}$ $2 \mathrm{SiO}_{2}$. The sodium impurity in the Corning 7059 glass, however, was less than $1 \%$, and more than one in quartz glass with flame reaction. The absorption wavelengths for $\mathrm{SiO}_{2}$ were $7.46,9.04,12.4$ and $21.3 \mu \mathrm{m}$. The highest absorption was $9.04 \mu \mathrm{m}$. The mentioned above, this wavelength difference of the peaks is dominated by the impurity.

\section{CONCLUSIONS}

The platinum infrared micro emitter shows that the temperature raised up to $600{ }^{\circ} \mathrm{C}$ at least. The emissivities of ceramics thin films on the platinum film are different from one of bulk targets and less than them. In Corning 7059 thin films, however, the higher emissivity of the film rather than the target emissivity is obtained at film thickness $6.7 \mu \mathrm{m}$ in wavelength $7-11 \mu \mathrm{m}$. The highest value of emissivity of the thick film is 0.96 at wavelength $9.5 \mu \mathrm{m}$. The Corning 7059 thin film emitter is suitable for gases detection in wavwlength 7-11 $\mu \mathrm{m}$. The infrared vibrational absorption wavelengths for the pollutant gases are 7.20 and $7.78 \mu \mathrm{m}$ of $\mathrm{CO}_{2}, 7.25$ and $10.07 \mu \mathrm{m}$ of $\mathrm{C}_{2} \mathrm{H}_{6}, 7.58 \mu \mathrm{m}$ of $\mathrm{NO}_{2}, 7.66 \mu \mathrm{m}$ of $\mathrm{CH}_{4}$ and $9.35 \mu \mathrm{m}$ of $\mathrm{SO}_{3}$.

\section{ACKNOWLEDGMENTS}

This research project was sponsored by government of Kanagawa Prefecture. The staffs thank guest researchers S. Kodato of Anritsu Corporation and K. Akimoto of Komyo Rikagaku Kogyo K.K. We would like to express our thanks to Mr. Nakahati of Nippon Barnes Company, Ltd. for his kindness. Mr. Tanigawa and Mr. Ueda, Nippon Barnes Company, Ltd., are acknowledged for the measurements of heated infrared radiator with thermography and advice of SA-200 spectroradiometer. (Manuscript received March 29, 1996, revised October 30, 1996)

(Manuscript received March 29, 1996, revised October 30,1996)

\section{REFERENCES}

[1] T. S. Eriksson, A. Hjortsberg and C. G. Granqvist, Sol. Energy Mater. 6, pp.191-199, 1982.

[2] K. Kusabiraki and Y. Shiraishi, J. de Phys., Colloque C9, supplément au $n^{\circ} 12$, Tome 43, pp.C9351-C9-354, 1982.

[3] F. Seronde, P. Echegut, J.P.Coutures and F. Gervais, Mater. Science and Engineering, B8, pp.315-327, 1991. 


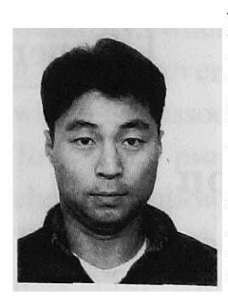

Masahiko Mitsuhashi received the B.S. degree in 1988 and the M.S. degree in 1990, in physics from Nihon University, Tokyo, Japan. $\mathrm{He}$ is currently a member of Photo-device Project in Kanagawa Industrial Technology Research Institute, Ebina, Japan. He is interested in Pt and diamond films.

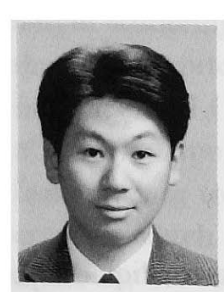

Seishiro Ohya received the B.S. degree in physics from Tokyo Metropolitan University, Tokyo, Japan, in 1985 . He is currently a member of Photo-device Project in Kanagawa Industrial Technology Research Institute, Ebina, Japan. He is interested in pulsed laser deposition of oxide films.

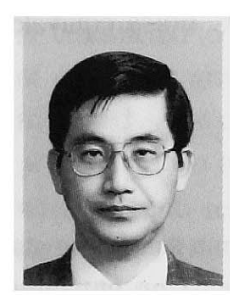

Shiro Karasawa (Member) $\mathrm{He}$ received the Ph.D. degree in 1979, in physics, from University of Tsukuba, Tsukuba, Japan. He is currently a leader of Photo-device Project in Kanagawa Industrial Technology Research Institute, Ebina, Japan. His current research interest is application of micromaching to optical and sensor devices. He is a member of the Spectroscopical Society of Japan and a member of the Japan Society of Applied Physics.

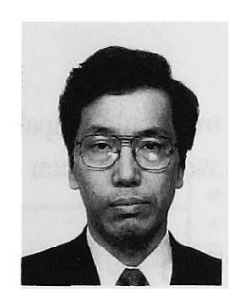

Kenji Akimoto received the B.S. degree in 1973 from Science University of Tokyo. He is currently with Komyo Rikagaku Kogyo K.K. His research work is the investigation of gas sensing systems using infrared absorption. From 1996, he is a guest researcher at Kanagawa Industrial Technology Research Institute, Ebina, Japan.

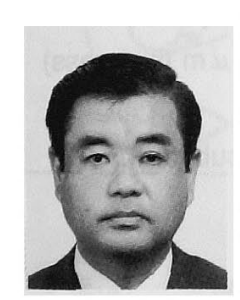

Masayuki Onoue received the B.E. degree in textile and high-polymer engineering from Tokyo University of Agriculture and Technology, Tokyo, Japan, in 1972. And qualified as a consulting Engineer in 1979 from the Agency of Science and Technology. His mainly research work is the investigation of dynamic needle thread tension and needle heating at sewing, and he is interested recently in measuring the infrared radiation.
He is currently with the Kanagawa Industrial Technology Research Institute, Ebina, Japan. He is a member of the Society of Fiber Science and Technology, Japan.

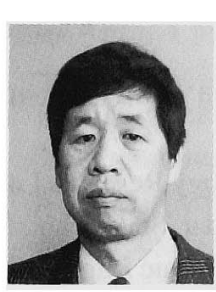

Setsuo Kodato (Member) He received the B.S. degree in electrical engineering, M.S. degree and D.E. degree in electronic engineering from Tokyo Institute of Technology, Tokyo, Japan, in 1971, 1974 and 1991, respectively. He joined Anritsu Corporation in 1974.

Since then he has been engaged in development of semiconductor devices and amorphous sensors. From 1993 to 1995 , he was a Visiting Professor at Muroran Institute of Technology, Hokkaido, Japan. From 1995, he is a guest researcher at Kanagawa Industrial Technology Research Institute, Ebina, japan. Currently, he is a Manager in the Research Laboratory at the Anritsu Corporation. 